\title{
The Relationship Between the Emotional Labor, Job Enthusiasm and Job Burnout of Pilates Instructors
}

\author{
Sang-il Lee ${ }^{1}$, Hae-in Seo ${ }^{2}$ \\ ${ }^{1}$ Instructor, Department of Physical Education, Graduate School of Soonchunhyang University, South \\ Korea,mdwbm@nate.com \\ ${ }^{2}$ Instructor, Department of Physical Education, Graduate School of Dankook University, South \\ Korea,dance1024@naver.com
}

Corresponding author: Hae-in Seo

\begin{abstract}
The purpose of this study is to investigate on the relationship between emotional labor, job enthusiasm, and job burnout of Pilates leaders. To this end, 232 Pilates instructors from three regions in Seoul, Gyeonggi, and Incheon were selected as samples used for analysis. For the data processing, correlation analysis, and multiple regression analysis were performed using the SPSS 23.0 statistical program to verify the hypothesis, and the following results were obtained. First, as a result of analyzing the effect of emotional labor (surface action, inner action) on the job passion of Pilates leaders, the effect of sub-factors of emotional labor, surface action, and inner action on positive $(+)$ job passion. appear. Therefore, it was confirmed that emotional labor partially affected job enthusiasm. Second, as a result of analyzing the effect of Pilates leader's emotional labor (superficial behavior, internal behavior) on job burnout (fatigue, cynicism, decreased sense of achievement), sub-factors of emotional labor, superficial behavior and internal behavior, it was job burnout. It was found to be a diminishing achievement variable, a sub-factor that had a negative (-) effect on emotional fatigue and no effect on cynicism. Therefore, it was confirmed that emotional labor had a partial effect on job burnout. Third, as a result of analyzing the effect of Pilates leaders' job enthusiasm on job burnout (decreased burnout, cynicism, and decreased achievement), job enthusiasm had a negative (-) effect on emotional fatigue and decreased sense of achievement, and was a factor in job burnout. It was found to be a variable that affects cynicism and does not appear to affect cynicism. Therefore, it was confirmed that job enthusiasm had a partial effect on job burnout.
\end{abstract}

Keywords: Pilates Instructor, Emotional Labor, Job Enthusiasm, Job Burnout

\section{Introduction}

Recently, modern people believe that various leisure and sports activities are essential to lead a healthy life as well as physical, psychological, and emotional stability, and they are trying to escape from stress. In addition, as leisure time increases due to the improvement of the standard of living and the introduction of a five-day work week, the number of people seeking to improve the quality of life is increasing[1]. As the importance of health was emphasized, various exercise programs were newly attracted attention, and from the 2000s, Pilates exercise, which maintains a balanced and harmonious body, began to be introduced to Korea as a health therapy by famous celebrities and sports stars[2].

Pilates was developed by German Joseph H. Pilates(1880 1967) in the early 1900's and is a movement that is constantly developing. Joseph Pilates, the first inventor of the Pilates exercise program,

Received: January 11, 2021; $1^{\text {st }}$ Review Result: February 25, 2021; $2^{\text {nd }}$ Review Result: April 14, 2021 Accepted: May 25, 2021 
began exercising as a child to find health while suffering from diseases such as asthma, tuberculosis, and rheumatism. He began diving, skiing, and gymnastics as a teenager. He became a professional boxer in 1912 and has since worked as a professional boxer in England. He has long studied how to strengthen the body through human physiological methods through the Human Movement System, and through this, he devised a new exercise method based on the yoga of the East and the physical fitness and mental training methods of the ancient Romans and Greeks[3]. During World War I, soldiers injured by the war complained of pain. Accordingly, Pilates was first introduced as a new exercise method and started with the purpose of rehabilitation to relax and strengthen the muscles of soldiers. Later, Joseph Pilates spread Pilates to the United States on the occasion of his exile to the United States in 1920. He opened the Pilates Circle of "Contrology" and attempted to spread it to the public[4].

Today, Pilates has established itself as a leisure culture and has been recognized by participants, proving the fact that it is constantly increasing.

In the survey on participation in national life sports in Ministry of Culture, Sports and Tourism[5], yoga/pilates were ranked in the top 3 in the rate of experience in daily sports related classes and lectures, indicating the recent public interest in Pilates and the role of leaders in charge of lectures is also important. have. In addition, the role of a leader is important for continuous participation after the lecture experience, and a leader with excellent skills and qualities can have a great influence on participants in sports activities[6].

As the weight of leisure increases, the number of centers specializing in pilates increases, and the role of the Pilates leader becomes very important and the number of Pilates leaders is also increasing. However, according to this rapidly increasing trend, the grievances of Pilates leaders are also increasing, and the phenomenon of leaving the leader in the middle is frequently occurring.

According to Korea Vocational Competency Development Institute[7], at the level of job subdivision where a lot of emotional labor is performed, 75 occupations are classified into 30 occupations where hosts and leaders such as sports and recreation instructors, announcers, and reporters perform a lot of emotional labor. It was analyzed to be included in Han Sang-geun[8]. In summary, it is an urgent concern to find a way to reduce the job burnout since its trend is increasing according to the emotional labor of Pilates instructors. In this way, the purpose of this study is to investigate on the effect of the Pilates leader's emotional labor on job enthusiasm and job burnout, as it was found that there is an intermediate variable called job enthusiasm in the relationship between emotional labor and job burnout[9].

Job burnout is caused by emotional labor. In other words, service workers psychologically cause emotional dissonance by expressing the emotions requested by the organization regardless of their actual emotions, and by experiencing a false person who considers them hypocritical, personal or job duties such as self-deprecation, depression, and alienation. It is put into a related maladjustment state[10]. Therefore, it is revealed that such job exhaustion can lead to phenomena such as lethargy, depression, insomnia and psychological and mental health problems as an increase in exhaustion, which has been mainly seen in service industry workers[11]. However, studies on pilates instructors, who are engaged in the service industry related to pilates, are still insufficient, so it is considered necessary to study this.

On the other hand, job enthusiasm can be viewed as a state of one's own mind that makes the job process full of vigor and passionate energy[12]. According to the research in [13], it can be seen that the higher the job enthusiasm of the Taekwondojang leader, the higher the job burnout. In the preceding studies (Seo-kyung Oh, Yoon Hye-hyun[14], Namki Kim, Heung Jeon, Jonggwan Lee[15], Hye-ri Myung, Hyeong-gon Kim[16]), the higher the job enthusiasm, the higher the job burnout. Has been shown to affect. As such, job enthusiasm was found to be a factor that lowers emotional labor, and in half, it was found to be a factor affected by job burnout.

In summarizing the above, it is judged that it is urgent to find a way to reduce the job burnout since the trend of job burnout is increasing according to the emotional labor of Pilates instructors. In this way, the purpose of this study is to investigate the effect of the Pilates leader's emotional labor on job 
enthusiasm and job burnout, as it is judged that there is an intermediate variable called job enthusiasm in the relationship between emotional labor and job burnout. It is significant in that it investigates the relationship among Pilates instructors, as studies on emotional labor, job enthusiasm, and job burnout are insufficient.

\section{Research Method}

\subsection{Research Subject}

The subjects of this study were selected from a population of Pilates instructors and people with Pilates related certifications with more than 1 year of leadership experience. After that, one of the nonprobability methods, convenience sampling, was used for about 10 weeks from January to March 2020. We sampled 250 working leaders. A total of 232 data were selected as valid samples, excluding 18 questionnaires with missing or incorrect answers among the collected data [Table 1].

[Table 1] Contents of the Questionnaire

\begin{tabular}{ccc}
\hline Configuration & Contents & Question \\
\hline \hline Demographic characteristics & Gender, Age, Working period & 3 \\
\hline Emotional labor & Surface behavior & 3 \\
& Inner behavior & 4 \\
\hline Job exhaustion & Job enthusiasm & 4 \\
& Emotional exhaustion & 4 \\
& Cynicism & 4 \\
\hline
\end{tabular}

\subsection{Investigation Tool}

The survey tool used to achieve the effect of the Pilates instructor's emotional labor on job enthusiasm and job burnout in this study was a questionnaire, and all variables and questions were composed based on previous studies that were consistent with the purpose of this study. The detailed contents of the questionnaire consisted of a total of 28 questions, including 3 questions on the demographic characteristics of the study subject, 7 questions on emotional labor, 6 questions on job enthusiasm, and 12 questions on job burnout.

\subsubsection{Emotionnal Labor}

To measure emotional labor, the ELS (Emotional Labor Scale) Grandey, (2000) scale used in Gilsteap's (2005) study was adapted and validated by Lee(2007). It was used by revising and supplementing it as a basis. Specifically, it was composed of a total of 9 questions, including 4 questions for inner behavior and 4 questions for superficial behavior, and was composed using a 5-point Likert scale. 


\subsubsection{Job Enthusiasm}

To measure job enthusiasm, based on the questionnaire that verified the validity in the studies of Kim Myeon-sik(2014) and Lee Jun-ho(2017), it was modified and supplemented according to the purpose of this study. Specifically, it was composed of a total of 6 questions in the job column, and was composed using a 5-point Likert scale.

\subsubsection{Job Exhaustion}

In order to measure job burnout, the Maslch Burnout Inventory-General Survey (MBI-GS) scale developed by Schaufeli et al. Based on the questionnaire that was verified for validity in the study of, it was modified and supplemented to suit the purpose of this study. Specifically, it consisted of a total of 15 questions including 5 emotional exhaustion, 5 cynicism, and 5 decreased sense of accomplishment, and was constructed using a 5-point Likert scale.

\subsection{Validity and Reliability}

In this study, in order to verify the suitability of the questionnaire prior to the application of the structured questionnaire, the content validity of the questionnaire was verified through an expert council consisting of 3 physical education professors and 2 pilates instructors. Afterwards, in order to check the validity and reliability of the measurement tool, in exploratory factor analysis, factors were estimated as main components, and items with factor loadings of .40 or less in the orthogonal rotation (Varimax) and analysis process, and factors loading of .40 or more for both factors, items with a commonality of .40 or less were deleted. Afterwards, the internal consistency reliability (Cronbach's $\alpha$ ) was verified, and the following results were obtained.

\subsubsection{Exploratory Factor Analysis and Reliability Analysis of Emotional Labor}

[Table 2] shows the results of the exploratory factor analysis and reliability analysis on emotional labor of Pilates instructors.

The initial question consisted of a total of 8 questions, which were extracted as two factors: superficial behavior and internal behavior, but one question (item 4) with factor loading of less than .40 was excluded from the final question. As a result of reliability analysis, all factors were above .70, indicating good reliability.

[Table 2] Exploratory Factor Analysis and Reliability Analysis of Emotional Labor

\begin{tabular}{|c|c|c|c|}
\hline Variable & Question & $\begin{array}{l}\text { Surface } \\
\text { behavior }\end{array}$ & $\begin{array}{l}\text { Inner } \\
\text { action }\end{array}$ \\
\hline \multirow{8}{*}{$\begin{array}{l}\text { Emotional } \\
\text { labor }\end{array}$} & 3. I find it hard to express my real feelings at work. & .917 & .205 \\
\hline & 4. I laugh more forcibly than for real at work. & .866 & .322 \\
\hline & 1. I often hide my real feelings at work. & .737 & .379 \\
\hline & 5..I always try to have a positive mindset due to the nature of my work. & .250 & .932 \\
\hline & 8. Always try to keep a good mood while performing work. & .301 & .899 \\
\hline & $\begin{array}{l}\text { 7. For the mutual interpersonal relationship that takes place at work, we strive to bring out } \\
\text { positive emotions from within. }\end{array}$ & .284 & .877 \\
\hline & 6. At work, try to create positive emotions in your mind. & .315 & .853 \\
\hline & Eigenvalues & 4.812 & 4.019 \\
\hline
\end{tabular}




\begin{tabular}{lccc}
\hline \hline Dispersion(\%) & & 45.484 & 45.484 \\
Accumulate(\%) & Cronbach's $\alpha$ & 43.914 & 89.398 \\
\cline { 2 - 5 } & C & .923 & .962 \\
\hline
\end{tabular}

$\mathrm{KOM}=.891$, Bartlett's Test $=2120.648, \mathrm{df}=45, \mathrm{sig}=.000$

\subsubsection{Exploratory Factor Analysis and Reliability Analysis of Job Enthusiasm}

[Table 3] shows the results of the exploratory factor analysis and reliability analysis of the Pilates instructor's job enthusiasm.

A total of 6 items were extracted as a single factor, and as a result of the reliability analysis of the final item, the reliability of the single factor was well over .70 .

[Table 3] Results of Exploratory Factor Analysis and Reliability Analysis of Job Enthusiasm

\begin{tabular}{|c|c|c|}
\hline Variable & Question & $\begin{array}{c}\text { Enthusiasm for } \\
\text { work }\end{array}$ \\
\hline \multirow{10}{*}{$\begin{array}{l}\text { Enthusiasm } \\
\text { for work }\end{array}$} & 3. I am always considerate to gain intimacy at work. & .916 \\
\hline & 6. I believe that I have a high passion for achieving my goals in my work. & .915 \\
\hline & 5. I handle complaints or problems while working in a respectful and friendly manner. & .908 \\
\hline & 2. I handle the given tasks so that there is no error. & .898 \\
\hline & 4. I always provide services for customer convenience from the customer's point of view. & .865 \\
\hline & 1. I am passionate about the work I have to do. & .846 \\
\hline & Eigenvalues & 4.128 \\
\hline & Dispersion $(\%)$ & 79.146 \\
\hline & Accumulate $(\%)$ & 79.146 \\
\hline & Cronbach's $\alpha$ & .919 \\
\hline
\end{tabular}

$\mathrm{KMO}=.912$, Bartlett's Test $=945.267, \mathrm{df}=35, \mathrm{sig}=.000$

\subsubsection{Exploratory Factor Analysis and Reliability Analysis of Job Burnout}

[Table 4] shows the results of the exploratory factor analysis and reliability analysis of the Pilates instructor's job burnout.

The initial items consisted of 15 items and were extracted as three factors: emotional exhaustion, cynicism, and decreased sense of achievement. However, the final item excluded 3 items (items 4, 10, and 14) with factor loadings of .40 or less. As a result of reliability analysis, all factors were above .70 indicating good reliability.

\subsection{Investigation Procedure}

In order to achieve the purpose of this study, the researcher visited the Pilates profession-related specialty stores in Seoul, Gyeonggi, and Incheon for about 10 weeks from January to March 2020. Prior to conducting the investigation, the person in charge of the Pilates specialty store asked for permission before visiting, and after sufficiently explaining the content, purpose and purpose of the study to the subject, 232 Pilates instructors who agreed to be selected as subjects and self-evaluation method (selfadministration) method), and then directly collected by the researcher. 
[Table 4] Exploratory Factor Analysis and Reliability Analysis of Job Burnout

\begin{tabular}{|c|c|c|c|c|}
\hline Variable & Question & $\begin{array}{l}\text { Emotional } \\
\text { exhaustion }\end{array}$ & Cynicism & $\begin{array}{c}\text { Decreased } \\
\text { sense of } \\
\text { achievement }\end{array}$ \\
\hline \multirow{16}{*}{ Burnout } & 2. I am completely exhausted when I get home from work. & .914 & .141 & .249 \\
\hline & 5. I am exhausted mentally and physically from doing my job. & .855 & .295 & .149 \\
\hline & 1. I am emotionally exhausted from my work. & .784 & .290 & .167 \\
\hline & $\begin{array}{l}\text { 3. I feel tired just thinking about waking up in the morning and going to } \\
\text { work. }\end{array}$ & .754 & .254 & .348 \\
\hline & 7. I am not enthusiastic about my work. & .223 & .916 & .204 \\
\hline & 6. I am losing interest in what I do. & .334 & .896 & .378 \\
\hline & 8. I am cynical about my contribution to my work. & .354 & .875 & .223 \\
\hline & 9. I doubt the importance of my job. & .265 & .854 & .235 \\
\hline & 11. I feel that I am not contributing to my current gym. & .189 & .190 & .935 \\
\hline & 15. I am not effectively performing my role in my current job. & .123 & .290 & .916 \\
\hline & 12. I feel that I am not good at work when I think about it. & .323 & .256 & .897 \\
\hline & 13. I do not feel proud when I have accomplished something in my job. & .278 & .240 & .846 \\
\hline & Eigenvalues & 3.912 & 3.792 & 3.393 \\
\hline & Dispersion $(\%)$ & 28.482 & 27.088 & 24.239 \\
\hline & Accumulate $(\%)$ & 28.482 & 55.571 & 79.810 \\
\hline & Cronbach's $\alpha$ & .913 & .927 & .909 \\
\hline
\end{tabular}

$\mathrm{KOM}=.901$, Bartlett's Test $=20454.604, \mathrm{df}=89, \mathrm{sig}=.000$

\subsection{Data Processing}

Among the questionnaires collected to achieve the purpose of this study, questionnaires that are judged to be unfaithful or unreliable are excluded, and questionnaires judged as reliable data are coded to use the statistical program SPSS 23.0 Version I did. The specific analysis method is as follows.

First, frequency analysis was performed to analyze the general characteristics of the subjects.

Second, exploratory factor analysis was conducted to secure the construct validity of the survey tool.

Third, reliability verification using Cronbach's a coefficient was conducted to find out the internal consistency of the lower variable.

Fourth, correlation analysis and multiple regression analysis were conducted to verify the relationship between the Pilates leader's emotional labor, job enthusiasm, and job burnout.

\section{Results}

\subsection{Correlation Analysis}

Prior to analyzing the causal relationship between emotional labor and job enthusiasm and job burnout, in this study, in order to investigate the structural relationship of each factor, the correlation and direction between the scales of each research unit were investigated for the potential variables whose single dimensionality was identified. For this purpose, the correlation coefficient was calculated through Pearson's momentum correlation analysis [Table 5]. 
[Table 5] Correlation Analysis between each Factor

\begin{tabular}{lcccccc}
\hline Variable & 1 & 2 & 3 & 4 & 5 & 6 \\
\hline \hline 1. Superficial behavior & 1 & & & & & \\
2. Inner behavior & $.989^{* *}$ & 1 & & & & \\
3. Job enthusiasm & $.808^{* *}$ & $.926^{* *}$ & 1 & & & \\
4. Emotional exhaustion & $.885^{* *}$ & $.967^{* *}$ & $.824^{* *}$ & 1 & & \\
5. Cynicism & $-391^{* *}$ & -.278 & -.312 & $-.356^{* *}$ & 1 & \\
6. Loss of sense of achievement & -.173 & -.119 & -.195 & -.296 & $.886^{* *}$ & 1 \\
\hline${ }^{*} \mathrm{p}<.05, * * \mathrm{p}<.01$ & & & & & &
\end{tabular}

Specifically, first, it was found that there was a statistically significant positive $(+)$ correlation between surface behavior, inner behavior, and job enthusiasm, which are sub-factors of emotional labor $(\mathrm{p}<.01)$. Second, there was a statistically significant positive $(+)$ correlation between the sub-factors of emotional labor such as superficial behavior, inner behavior, and the sub-factors of job burnout such as emotional exhaustion, cynicism, and decreased sense of achievement $(\mathrm{p}<.01)$. Lastly, there was a statistically significant positive $(+)$ correlation between job enthusiasm and job burnout, such as emotional exhaustion, cynicism, and decreased sense of achievement $(\mathrm{p}<.01)$.

\subsection{The Influence of Pilates Leader's Emotional Labor on Job Enthusiasm}

To find out the causal relationship between the Pilates leader's emotional labor and job enthusiasm, the results of multiple regression analysis were shown in [Table 6]. Specifically, the explanatory power of the Pilates instructor's emotional labor predicting the sub-factors of job enthusiasm was $53.5 \%$ $\left(\mathrm{R}^{2}=.535\right)$, and the $\mathrm{F}$ value was 53.212 , indicating that the regression equation was significant at the $\mathrm{p}<.001$ level. . In detail, among the sub-factors of emotional labor, surface behavior $(\mathrm{t}=4.580, \mathrm{p}<.01)$ and inner behavior $(t=3.783, p<.05)$ were found to be variables that influence job enthusiasm. $\beta=.353$, $\beta=.250$.

[Table 6] The Effect of Emotional Labor on Job Enthusiasm

\begin{tabular}{|c|c|c|c|c|c|}
\hline & & B & Std E & $\beta$ & $\mathrm{t}$ \\
\hline \multirow{3}{*}{$\begin{array}{c}\text { Job } \\
\text { enthusiasm }\end{array}$} & (Constant) & 1.537 & .374 & & $5.833 * * *$ \\
\hline & Superficial behavior & .465 & .277 & .353 & $4.580 * *$ \\
\hline & Inner behavior & .344 & .273 & .250 & $3.783^{*}$ \\
\hline
\end{tabular}

${ }^{*} \mathrm{p}<.05,{ }^{* *} \mathrm{p}<.01, * * * \mathrm{p}<.001$

\subsection{The Effect of Pilates Leader's Emotional Labor on Job Burnout}

The results of multiple regression analysis to find out the causal relationship between the emotional labor and job burnout of Pilates leaders are shown in [Table 7].

Specifically, first, the explanatory power of predicting emotional exhaustion, which is a sub-factor of 
job burnout due to emotional labor, is explained as $21.0 \%\left(\mathrm{R}^{2}=.210\right)$, and the $\mathrm{F}$ value is 6.773 , where the regression equation is significant at $\mathrm{p}<.01$ level. Appeared. In detail, the sub-factors of emotional labor, surface behavior $(\mathrm{t}=-2.234, \mathrm{p}<.01)$ and inner behavior $(\mathrm{t}=-2.201, \mathrm{p}<.05)$ were found to be variables that influence emotional exhaustion. Each was found to be $\beta=-.324$ and $\beta=-.395$. Second, the explanatory power for predicting cynicism, which is a sub-factor of job burnout, is explained as $18.6 \%\left(\mathrm{R}^{2}=.186\right)$, and the $\mathrm{F}$ value was .354 , indicating that the regression equation was not significant. Third, the explanatory power of predicting the decrease in achievement loss, which is a sub-factor of job burnout by emotional labor, is explained as $33.5 \%\left(\mathrm{R}^{2}=.335\right)$, and the $\mathrm{F}$ value was 5.669 , indicating that the regression equation was significant at the $\mathrm{p}<.01$ level. Specifically, among the sub-factors of emotional labor, surface behavior $(\mathrm{t}=-3.745, \mathrm{p}<.01)$ was found to be a variable affecting the decrease in achievement, and the explanatory power was $\beta=-.288$.

[Table 7] The Effect of Emotional Labor on Job Burnout

\begin{tabular}{|c|c|c|c|c|c|}
\hline & & $\mathrm{B}$ & Std E & $\beta$ & $\mathrm{t}$ \\
\hline & (Constant) & 3.768 & .367 & & $6.831 * * *$ \\
\hline \multirow[t]{2}{*}{$\begin{array}{l}\text { Emotional } \\
\text { exhaustion }\end{array}$} & Superficial behavior & -.243 & .271 & -.324 & $-2.234^{* *}$ \\
\hline & Inner behavior & .381 & .273 & -.395 & $-2.201 *$ \\
\hline \multicolumn{6}{|c|}{$\mathrm{R}^{2}=.210, \mathrm{~F}=6.773^{* *}$} \\
\hline \multirow{3}{*}{ Cynicism } & (Constant) & 3.525 & .356 & & $4.543^{* * *}$ \\
\hline & Superficial behavior & -.286 & .263 & -.169 & -.384 \\
\hline & Inner behavior & -.271 & .323 & -.162 & -.265 \\
\hline \multicolumn{6}{|c|}{$\mathrm{R}^{2}=.186, \mathrm{~F}=.354$} \\
\hline \multirow{3}{*}{$\begin{array}{l}\text { Loss of sense of } \\
\text { achievement }\end{array}$} & (Constant) & 3.651 & .278 & & $6.324 * * *$ \\
\hline & Superficial behavior & -.325 & .265 & -.288 & $-3.745^{* *}$ \\
\hline & Inner behavior & .254 & .234 & -.216 & -2.354 \\
\hline & & $\mathrm{R}^{2}=.3$ & $69 * *$ & & \\
\hline
\end{tabular}

$* \mathrm{p}<.05, * * \mathrm{p}<.01, * * * \mathrm{p}<.001$

\subsection{The Effect of Pilates Leaders' Job Enthusiasm on Job Burnout}

In order to find out the causal relationship between the Pilates instructor's job enthusiasm and job burnout, the results of multiple regression analysis were shown in [Table 8].

Specifically, first, the explanatory power of predicting work relations, where job enthusiasm is a subfactor of job stress, is explained as $38.3 \%\left(\mathrm{R}^{2}=.383\right)$, and the $\mathrm{F}$ value is 6.764 , where the regression equation is significant at $\mathrm{p}<.01$ level. Appeared. In detail, job enthusiasm $(\mathrm{t}=-2.253, \mathrm{p}<.01)$ was found to be a variable affecting emotional exhaustion, and explanatory power was found to be $\beta=-.267$. Second, the explanatory power for predicting cynicism, which is a sub-factor of job burnout, was explained as $22.2 \%\left(\mathrm{R}^{2}=.222\right)$, and the $\mathrm{F}$ value was 2.436 , indicating that the regression equation was not significant. Third, the explanatory power for predicting the decrease in achievement loss, which is a sub-factor of job burnout, was explained by $31.3 \%\left(\mathrm{R}^{2}=.313\right)$, and the $\mathrm{F}$ value was 7.653 , indicating that the regression equation was significant at the $\mathrm{p}<.001$ level. In detail, job enthusiasm $(\mathrm{t}=-3.214, \mathrm{p}<.001)$ was found to be a variable affecting the decrease in achievement, and the explanatory power was $\beta=-.348$. 
[Table 8] The Effect of Job Enthusiasm on Job Burnout

\begin{tabular}{|c|c|c|c|c|c|}
\hline & & $\mathrm{B}$ & Std E & $\beta$ & $\mathrm{t}$ \\
\hline \multirow{2}{*}{ Emotional exhaustion } & (Constant) & 3.286 & .377 & & $5.845^{* * *}$ \\
\hline & Job enthusiasm & -.445 & .341 & -.267 & $-2.253 * *$ \\
\hline \multicolumn{6}{|c|}{$\mathrm{R}^{2}=.383, \mathrm{~F}=6.764 *$} \\
\hline \multirow{2}{*}{ Cynicism } & (Constant) & 3.712 & .357 & & $4.256^{* * *}$ \\
\hline & Job enthusiasm & -.258 & .234 & -.226 & -2.205 \\
\hline \multicolumn{6}{|c|}{$\mathrm{R}^{2}=.222, \mathrm{~F}=2.436$} \\
\hline \multirow{2}{*}{$\begin{array}{l}\text { Loss of sense of } \\
\text { achievement }\end{array}$} & (Constant) & 3.840 & .448 & & $6.649 * * *$ \\
\hline & Job enthusiasm & -.334 & .180 & -.348 & $-3.214 * * *$ \\
\hline \multicolumn{6}{|c|}{$\mathrm{R}^{2}=.313, \mathrm{~F}=7.653 * * *$} \\
\hline
\end{tabular}

$* * \mathrm{p}<.01, * * * \mathrm{p}<.001$

\section{Argument}

This study examined the relationship between the emotional labor of Pilates leaders and job enthusiasm and job burnout. In order to achieve these research objectives, the following discussions were gathered from the analysis results of the proposed research hypothesis.

\subsection{The Influence of Pilates Instructors on Emotional Labor and Job Enthusiasm}

As a result of conducting multiple regression analysis to see how it affects the Pilates instructor's emotional labor and job enthusiasm, it was found that emotional labor (surface behavior, inner behavior) had a significant effect on job enthusiasm. Looking specifically at this, it partially supports the results of various preceding studies ([17-19]) that emotional labor influences job enthusiasm.

On the other hand, it should be noted that in this study, the attitude of customers who use Pilates can be interpreted as the biggest factor that can induce a leader's job enthusiasm. It is believed that Pilates instructors are experiencing emotional labor such as superficial behavior and inner behavior due to constant stress.

In summarizing the above results, it can be seen that when the feelings felt on the surface and the feelings felt internally, the feelings felt emotionally become exhausted and the enthusiasm for the job decreases. Therefore, it is considered that job enthusiasm is very important for employees with high emotional labor to achieve goals that can enhance job enthusiasm and for personal growth and development.

\subsection{The Influence of Pilates Instructor on Emotional Labor and Job Burnout}

As a result of conducting multiple regression analysis to see how it affects the emotional labor and job burnout of Pilates instructors, emotional labor (surface behavior, inner behavior) was found to have a significant effect on job burnout. Specifically, it partially supports the results of various previous studies ([20-22]) that emotional labor has an effect on job burnout.

On the other hand, it should be noted in the results of this study that the higher the emotional labor, the lower the job burnout. In general, the superficial behavior is highly related to the emotional 
dissonance, hiding the inner mind and expressing the emotion that meets the expression rules only on the outside. Because of this, inconsistency occurs[23].

Taking the above results together, it is thought that when the Pilates leaders become aware of emotional labor, they can provide good service with bright and positive behavior to customers when job exhaustion occurs.

\subsection{The Influence of Pilates Leaders' Job Enthusiasm on Job Burnout}

As a result of conducting multiple regression analysis to see how it affects the Pilates instructor's job enthusiasm and job burnout, it was found that job enthusiasm had a significant effect on job burnout. Specifically, it partially supports the results of various previous studies[24] that job enthusiasm affects job burnout.

On the other hand, these findings show that job enthusiasm not only affects job burnout, but also, due to the characteristics of Pilates instructors, job enthusiasm can increase when necessary support from colleagues and managers is received. When this enthusiasm rises, it can be seen that the job is not exhausted by working without knowing that it is difficult or difficult while teaching.

Taking the above results together, it is believed that a concrete plan is needed to increase job enthusiasm in order for Pilates leaders to perform their duties with less emotional exhaustion and loss of achievement.

\section{Conclusion}

In order to find out the relationship between emotional labor, job enthusiasm, and job burnout for Pilates leaders, 232 Pilates instructors were subjected to computer processing according to the purpose of data analysis. As an analysis method, after demographic frequency analysis, exploratory factor analysis, and reliability analysis, correlation analysis and multiple regression analysis were conducted to verify the hypothesis. The following results were derived.

First, as a result of analyzing the effect of emotional labor (surface behavior, inner behavior) on the job enthusiasm of Pilates leaders, it was found that the sub-factors of emotional labor, surface behavior and inner behavior, had a positive $(+)$ effect on job enthusiasm. appear. Therefore, it was confirmed that emotional labor partially affected job enthusiasm.

Second, as a result of analyzing the effect of Pilates leaders emotional labor (surface behavior, inner behavior) on job burnout (feeling exhaustion, cynicism, decreased sense of achievement), the subfactors of emotional labor, surface behavior and inner behavior, were job burnout. It was found that it was a variable that had a negative (-) effect on emotional exhaustion and decreased sense of achievement, which were the sub-factors of, and did not affect the cynicism. Therefore, it was confirmed that emotional labor has a partial effect on job burnout.

Third, as a result of analyzing the effect of the Pilates leaders job enthusiasm on job burnout (feeling exhaustion, cynicism, decreased achievement loss), job enthusiasm has a negative (-) effect on emotional exhaustion and decreased achievement feeling, which are sub-factors of job burnout. It was found to be a variable that had an effect on cynicism, and it did not appear to have an effect on cynicism. Therefore, it was confirmed that job enthusiasm has a partial effect on job burnout.

Based on the results of this study, the following suggestions for follow-up studies were made.

First, since this study was limited to leaders engaged in Pilates in the Gyeonggi and Incheon areas, it is considered meaningful to expand the scope of the research subject in subsequent studies.

Second, in this study, the subject was limited to Pilates instructors, but it is also considered meaningful to expand the subject to elite Pilates instructors. 


\section{References}

[1] Hye-suk Shin, Soo-il Oh, The Relationship of Participation Satisfaction, Leisure Flow and Life Satisfaction according to Participation in Life Dance, Journal of Sport and Leisure Studies, (2007), Vol.30, pp.951-962, UCI : G704000763.2007.30.0.045

[2] Yun-kyung Lee, Eun-hye Kim, A Case Study on Curriculum Development for the Humanistic Pilates Classes as a Liberal Arts, The Korean Journal of Physical Education, (2015), Vol.54, No.5, pp.345-366, UCI : G704000541.2015.54.5.051

[3] Ji-eun Yoon, The Influence of Pilates Participants' Self-Efficacy on Self-Resilience and Willingness to Continue Exercise, Ewha Womans University Graduate School of Education, Master's thesis, (2021)

[4] Jin-Bae Bae, The effect of Pilates exercise on body shape, physical fitness, and muscle activity of trunk muscles in premenopausal and postmenopausal middle-aged women, Daegu Catholic University Graduate School, Doctoral Dissertation, (2009)

[5] '2018 Quality of Life Poll'. Ministry of Culture, Sports and Tourism, (2018)

[6] Kim Kyung-sook, Social Sports Leader Theory, Daekyung Book, (2000)

[7] Study on occupational indicators in Korea, Korea Vocational Competency Development Institute, (2013)

[8] Han Sang-geun, A Study on the Occupational Characteristics of Emotional Labor in Korea, The Journal of Labor Studies, (2016), Vol.32, No.4, pp.5-27.

[9] Songhee Lee, A study on the emotional labor and job stress of department store salespersons, Kyunghee University Business School, Master's thesis, (2011)

[10] Soo-yeon Lee, Hae-Sul Yang, The Relations of Emotional Labor to Emotional Exhaustion and Turnover Intention in Call Center Workers, Journal of the Korea Contents Association, (2008), Vol.8, No.4, pp.197-210, http://dx.doi.org/10.5392/JKCA.2008.8.4.197

[11] Young-gyun Shim, Ji-Tae Kim, Effects of Role Stress on Emotional Labor and Burnout Syndrome of Disability Taekwondo Instructor, The Korean Journal of Physical Education, (2018), Vol.57, No.6, pp.323-334, DOI: 10.23949/kjpe.2018.11.57.6.24

[12] Hyun-ryun Kim, Ji-tae Kim, Relationship among Positive Psychological Capital, Job Enthusiasm, and Job Stress of Instructors for Adapted Physical Activity(APA), Journal of Sport and Leisure Studies, (2019), No.78, pp.243-253, DOI : $10.51979 /$ KSSLS.2019.10.78.243

[13] Il-gu Yang, The relationship among emotional labor, job enthusiasm and job burnout of Taekwondo dojang leaders, The Korean Society of Sports Science, (2019), Vol.28, No.6, pp.349-360, DOI : 10.35159/kjss.2019.12.28.6.349

[14] Seo-kyung Oh, Yoon Hye-hyun, The effect of face sensitivity of full-service restaurant workers on job enthusiasm, job burnout and job turnover intention, Hotel Management Studies, (2014), Vol.23, No.3, pp.61-81.

[15] Namki Kim, Heung Jeon, Jonggwan Lee, The influence of Emotional Labor on Turnover intention and Customer Orientation Mediated by Burnout and Work Engagement : The Moderating effect of reward on manager at support centers for startup, Asia-Pacific Journal of Business Venturing and Entrepreneurship, (2015), Vol.10, No.1, pp.153165, DOI : 10.16972/apjbve.10.1.201502.153

[16] Hey-Ree Myung, Hyounggon Kim, A Study on the Moderating Effect of Mindfulness in the Effect of Airline Cabin Crew's Emotional Exhaustion on Job Enthusiasm: Focused on K Airlines, Journal of Tourism and Leisure Research, (2020), Vol.32, No.11, pp.283-302.

[17] Ahn Jae-seok, Yu Gwang-gil, Structural Model Analysis on the Emotional Labor, Emotional Dissonance, Job Engagement and Innovative Behavior in the Soccer Instructors, The Korean Society of Sports Science, (2019), Vol.28, No.2, pp.545-560, DOI : 10.35159/kjss.2019.04.28.2.545

[18] Kim Seong-yeon, Park Jong-cheol, The Effects of Hospital Service Employees' Emotional Labor on Enthusiasm and Customer Orientation: The Focus on Mediating Role of Emotional Expression Rules and Emotional Regulation, 
Journal of Product Research, (2019), Vol.37, No. 6, pp.95-106, DOI : 10.36345/kacst.2019.37.6.011

[19] Jo Joo-eun, Relationship Between Emotional Labor Affected Job Engagement and Organizational Commitment of Airline Service Employees, International Journal of Tourism Management and Sciences, (2016), Vol.31, No.7, pp.275293, http://dx.doi.org/10.21719/KJTR.31.7.14

[20] Dongsu Ryu, Sujeong Kim, (A)Case Study on Emotional Labor and Exhaustion from Work of Taekwondo Gym Instructors, The Journal of the Korea Contents Association, (2016), Vol.16, No.8, pp.611-623, https://doi.org/10.5392/JKCA.2016.16.08.611

[21] Lee Jeong-tak, Relationships Between Emotional Labor, Job Stress and Job Burnout of Recreation Leaders, The Korean Society of Sports Science, (2015), Vol.24, No.2, pp.291-303, UCI : G704-001369.2015.24.2.050

[22] Kim Yong-soo, The relationship between job stress, job satisfaction and job burnout according to emotional labor of sports center workers, Journal of Sport and Leisure Studies, (2012), Vol.47, No.1, pp.127-144, UCI : G704000763.2012..47.077

[23] A. A. Grandey, Emotion regulation in the workplace: A new way to conceptualize emotional labor, Journal of Occupational Health Psychology, (2000), Vol.5, No.1, pp.95-110, https://doi.org/10.1037/1076-8998.5.1.95

[24] Cho Sung-jin, Ahn Joo-mi, Lee Jun-woo, The Influence of Fitness Center Employees's Social-Face Sensitivity on Job Engagement and Job Burnout, Global Cultural Contents, (2015), No.18, pp.239-262, UCI : G704SER000003070.2015..18.012 